\title{
A Prospective Hospital Based Study of Ascaris Lumbricoides in Adults: Our Ten Years' Experience From A Highly Endemic Area of India
}

\author{
Khurshid Ahmad Ganaie ${ }^{1}$, Suraya Kounser ${ }^{2}$, Yawar Zahoor ${ }^{3}$ \\ ${ }^{1}$ Consultant, Department of General Surgery, Health Services, J\&K, ${ }^{2}$ Senior Resident, Postgraduate, Department of \\ Ophthalmology, SKIMS, Medical College and Hospital Bemina, Srinagar, ${ }^{3}$ Senior Resident, Postgraduate, Department of \\ Surgery, Moulana Azad Medical College Delhi, India
}

Corresponding author: Dr Khurshid Ahmad Ganaie, Sholipora Budgam, 191111, J\&K, India.

DOI: $10.21276 / \mathrm{ijcmsr}$ 2018.3.2.39

How to cite this article: Khurshid Ahmad Ganaie, Suraya Kounser, Yawar Zahoor. A prospective hospital based study of ascaris lumbricoides in adults: our ten years' experience from a highly endemic area of India. International Journal of Contemporary Medicine Surgery and Radiology. 2018;3(2):B166-B170.

\section{A B S T R A C T}

Introduction: As an obligate internal parasite of humans, Ascaris lumbricoides can theoretically be found wherever humans are present. The ascariasis is one of the most cosmopolitan intestinal parasite infections, and its biggest prevalence is observed in the tropical and subtropical areas. We are presenting a study emphasizing on abdominal problems due to ascariasis lumbricoides in adult patients, which has not been conducted so far in detail in the past.

Material and Methods: A total of 254 patients of roundworm infestation were included in this study from 2008-2018 prospectively. All these patients were more than 18 years of age and presented with one or other abdominal complaint due to ascaris lumbricoides. After properly diagnosing the disease, treatment was initiated subsequently depending upon the condition of the patient. Majority of the patients were managed conservatively. Rest of the cases were managed by endoscopic intervention or by surgical (open or laproscopic) intervention.

Results: Out of 254 patients, 164 patients (65\%) presented with hepato-biliary disease. Of these 164 cases,129 patients (79\%) had biliary colic, 25 patients (15\%) had cholangitis, $8(5 \%)$ patients presented with worm induced acalcular cholecystitis, and 2(1\%) patients presented with liver abscess. 49 (19\%) patients out of 254 patients presented with pancreatic disease, and $27(10.5 \%)$ patients presented to us with intestinal obstruction-20 had sub-acute intestinal obstruction and 7 patients presented with acute obstruction. Out of total 254 patients, $7(2.7 \%)$ patients presented with peritonitis (perforation), 5 ( $2 \%$ ) patients presented with acute appendicitis, and $2(0.8 \%)$ patients had meckle's diverticulitis.

Conclusion: Ascaris lumbricoides can present with wide range of acute or chronic abdominal diseases in adult patients. Thus a clinician in emergency department should consider ascaris lumbricoides infestation as one of the differential diagnosis in case of acute abdomen in adults in an endemic area, which otherwise he/she is likely to ignore in the first contact.

Key words: Ascaris lumbricoides, Hepato-biliary disease, Intestinal obstruction, Peritonitis.

\section{INTRODUCTION}

Ascaris lumbricoides infections have been reported in more than 150 countries across the globe, particularly in tropic, subtropic and temperate regions. Approximately 1.4 billion people worldwide are infected, 4 million of whom live in the United States.Ascaris lumbricoides (AL) is the most common helminth affecting humans and causing important medical and social problems especially in the under-developing countries $^{1-2}$. Ascaris lumbricoides infestation occurs in all age groups but more common in children of preschool age $\mathrm{a}^{3}$. As an obligate internal parasite of humans, ascaris lumbricoides can theoretically be found wherever humans are present $t^{4}$. When environment becomes intolerable for their living, they migrate to more appropriate areas of intestinal tract. Ascaris lumbricoides may cause serious problems at this migration including pancreatitis, cholecystitis, liver abscess, intestinal obstruction and even its perforation ${ }^{5-6}$. Diagnosis with clinical symptoms and hematological investigation frequently is not possible. X-ray may show air fluid levels. USG may show two pairs of echogenic tubular structures (railway track) longitudinally and bull's eye horizontally ${ }^{1,7}$. Tubular structures may have active movements that could make diagnosis easily. USG is a simple and reliable method for diagnosis of ascaris lumbricoides obstruction ${ }^{5,8}$.

Among the intestinal parasitism, the ascaris lumbricoides is a nematode which is one of the parasitosis of wide diffusion in the world: the ascariasis. Ascaris lumbricoides is the most prevalent and the largest of the intestinal nematodes that infect humans. This illness is characterized by variable symptomatology; it is generally asymptomatic in the adult, and it is in children where we see the most florid clinical presentation and the complications of this illness. As most of the intestinal parasite infections, the ascariasis prevails and 
is endemic in areas lacking of sanitary infrastructure, with precarious housings, poverty and ignorance 9 .

The most common acute complication of ascaris lumbricoides is intestinal obstruction in younger age group. The rate of mortality from intestinal obstruction is $5.7 \%$ below the age of 10 years $^{10}$. In adults the most common complication is hepato-biliary and pancreatic disease. Symptoms related to the migration of adult worms into the biliary tree can cause abdominal pain, biliary colic, acalculous cholecystitis, ascending cholangitis, obstructive jaundice, or bile duct perforation with peritonitis. Strictures of the biliary tree may occur ${ }^{11}$. Hepatic abscesses can also result ${ }^{12}$. Retained worm fragments can serve as a nidus for recurrent pyogenic cholangitis. The pancreatic duct may also be obstructed, leading to pancreatitis, and the appendix resulting in appendicitis. Occasionally, migrating adult worms emerge from the mouth, nose, lacrimal ducts, umbilicus or inguinal canal. High fever, diarrhea, spicy foods, anesthesia and other stresses have all been associated with an increased likelihood of worm migration ${ }^{13}$.

Partial intestinal obstruction from ascaris lumbricoides may resolve spontaneously with the conservative treatment including bowel rest, intravenous fluids, and nasogastric decompressing ${ }^{14}$. When mechanical obstruction persists, bolus of worm acts a fixed point, and leads to intussusception or volvulus. Ascaris may also excrete neurotoxins and anaphylatoxins leading to small bowel spasticity and inflammation. These toxins may induce the mechanical obstruction as well ${ }^{15-16}$. Volvulus, intussusception or increasing pressure to the intestinal wall causes necrosis ${ }^{17}$. In case of necrosis, resection and primary anastomosis are necessary. Clinical disease is largely restricted to individuals with a high worm load ${ }^{18}$. When symptoms do occur, they relate either to the larval migration stage or to the adult worm intestinal stage. Pathophysiologic mechanisms include

- Direct tissue damage

- The immunologic response of the host to infection with larvae, eggs or adult worms ${ }^{19}$

- Obstruction of an orifice or the lumen of the gastrointestinal tract by an aggregation of worms

- Nutritional sequelae of infection ${ }^{13}$

Hereby, we are presenting a study emphasizing on abdominal problems due to ascariasis lumbricoides in adult patients, which has not been conducted so far in detail in the past.

\section{MATERIAL AND METHODS}

The study was conducted prospectively in the department of general surgery SMHS hospital of Govt. Medical College Srinagar Kashmir (India) from 2008 to 2018. The study was approved by ethical committee of our institution. Only those patients were included in the study whose age was more than 18 years. Study was conducted on 254 adult patients irrespective of gender having abdominal complaint due to ascaris lumbrecoides infestation. All these patients presented to our emergency department with abdominal complaint as a result of ascaris infestation. The diagnosis was made by USG (ultrasonography) in majority of cases. Other diagnostic modality used was stool examination for ascaris ova, X-Ray abdomen and ERCP. Some cases were diagnosed intra-operatively (peritonitis cases). All the patients diagnosed of hepato-biliary-pancreatic disease were treated initially with conservative method. Those patients with USG (ultrasonography) documentation of ascaris were given anti-helminthic prior to endoscopic procedure. Endoscopic examinations were done by side-viewing flexible duodenoscope. The indications for ERCP were:-

a) Failure to eradicate the extra-hepatic biliary system of worms after 4 weeks of conservative treatment.

b) Persistence of jaundice or deteriorating symptoms in presence of biliary ascaris.

Dormia basket was used to retrieve the worms. Surgical exploration were reserved in those cases only were ERCP failed to remove the worms and having complications like deteriorating cholangitis, liver abscess formation etc. All the patients of suspected intestinal obstruction were initially subjected to conservative treatment -nil by mouth, intravenous fluid, nasogastric tube aspiration, rectal enemas (glycerine + liquid paraffin enema) and anti-helminthic drugs through nasogastric tube, depending upon the clinical condition and severity of obstruction. They were closely monitored with assessment of vital parameters, abdominal girth measurement and serial abdominal $\mathrm{X}$-ray. Clinical improvement was defined as a decrease in abdominal pain and distension, decrease in abdominal girth and associated passage of flatus or stool with or without expulsion of worms. The Radiological improvement was defined as a decrease in number of dilated bowel loops or decrease in the diameter of dilated small bowel. Patients were considered for surgical intervention if- there was any deterioration on clinical parameters.

In patients with peritonitis (perforation peritonitis) as a result of ascariasis complication, surgical exploration was done on emergency basis depended upon the clinical status of the patient. Patients having worms in gall bladder were operated on elective basis (laproscopic cholecystectomy was done). Anti-helminthic therapy was given to all patients in follow up period and were advised to take it at regular basis afterwards at home.

\section{STATISTICAL ANALYSIS}

Descriptive statistics like mean and percentages were used for the analysis.

\section{RESULTS}

The mean age of patients in our study was 27.9 (range 18-69 years) with S.D of 8 years. Out of 254 patients 170 $(67 \%)$ were females and $84(33 \%)$ patients were males (male: female ratio 1:2). In our study of 254 patients, we found 164 (65\%) patients who presented with hepato-biliary disease (Figure-1). Out of these 129 (79\%) patients had biliary colic, 25 (15\%) patients had cholangitis, 8(5\%) patients presented with acalcular cholecystitis, and 2 (1\%) patients presented with liver abscess. Out of total 254 patients 49 (19\%) patients presented with pancreatic disease. 48 (98\%) of these patients presented with acute pancreatitis and 1 (2\%) patient presented with pseudo cyst of pancrease. 27 (10.5\%) patients out of total 254 patients presented to us with intestinal obstruction (Figure-2). 20(74\%) patients 


\begin{tabular}{|l|c|}
\hline Clinical diagnosis & No. of patients \\
\hline Hepato-biliary-pancreatic disease & $32 / 254$ \\
CBD exploration for failed ERCP or persistant cholangitis & 21 \\
Gall bladder worms & 8 \\
Liver abscess & 2 \\
Pseudocyst pancrease & 1 \\
\hline Intestinal obstruction (acute) & $7 / 254$ \\
\hline Peritonitis & $7 / 254$ \\
\hline Appendicitis Table-1: Indications of surgery & $5 / 254$ \\
\hline Meckle's diverticulitis & $2 / 254$ \\
\hline \multicolumn{2}{|}{} \\
\hline
\end{tabular}

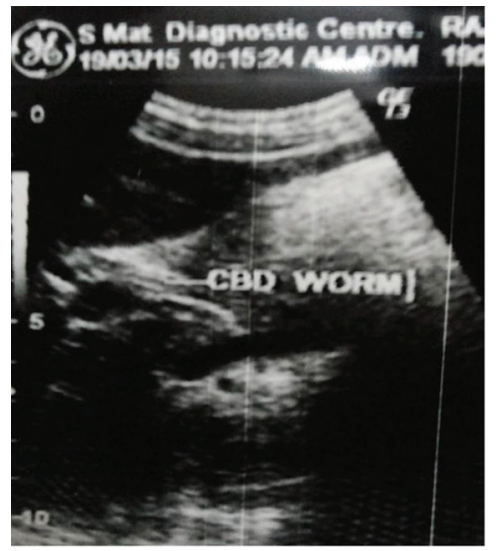

Figure-1: USG showing intestinal ascariasis

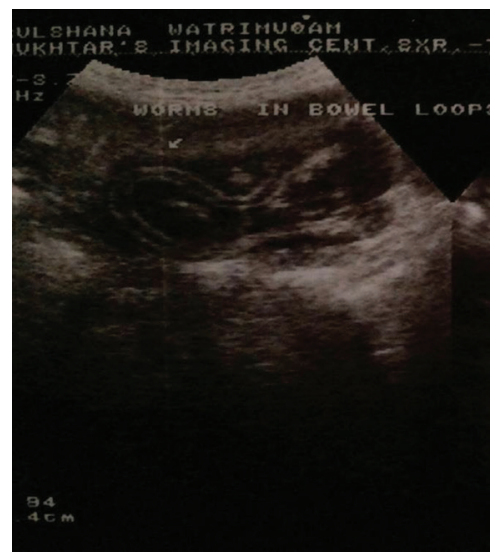

Figure-2: USG showing worm in CBD

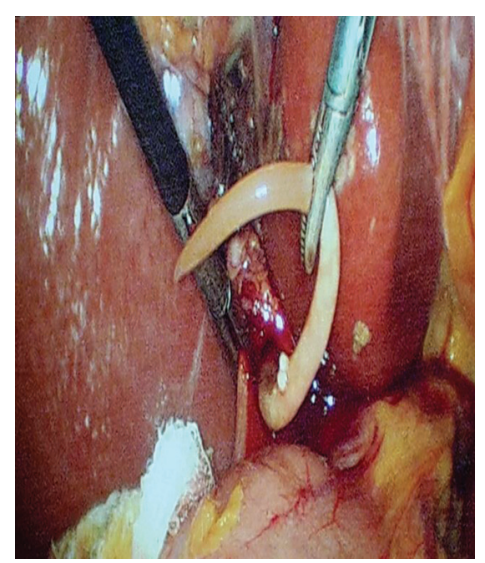

Figure-3: Worm extracted from CBD

out of these 27 had sub-acute intestinal obstruction and 7 (26\%) patients presented with acute obstruction (5 patients

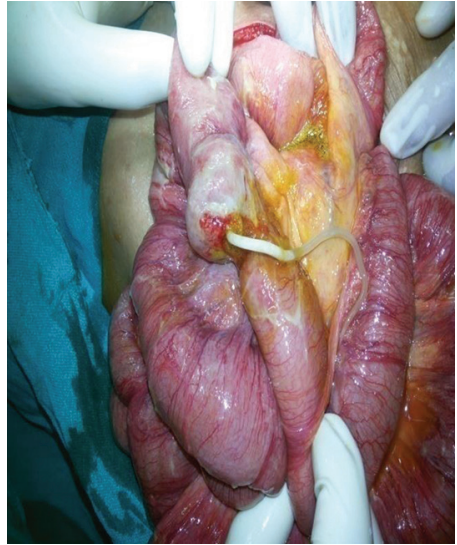

Figure-4: Worm causing peritonitis

had bolus obstruction and 2 patients had gangrene of bowel intra-operatively). In our study out of total 254 patients, 7 (2.7\%) patients presented with peritonitis (perforation), 5 (2\%) patients presented with acute appendicitis and 2 (0.8\%) patients had meckle's diverticulitis.

160 (63\%) patients out of 254 patients were managed conservatively ( $>90 \%$ of these patients were having hepatobiliary and pancreatic disease). In 41 (16\%) patients we needed ERCP (diagnostic as well as thearupatic). Surgical intervention was required in 53 (21\%) patients (Table-1). Out of these 53 patients, laproscopic procedure (Figure-3) was done in 33 patients ( 19 common bile duct explorations, 8 cholecystectomies, 5 appendectomies and 1 cystogastrostomy), and other 20 patients under-went exploratory laprotomies (seven with peritonitis (Figure-4), seven with acute intestinal obstruction patients, two common bile duct explorations (lap. converted to open), two with meckle's diverticulitis and two patients with liver abscess). 2 patients died in our study (one patient with pyogenic cholangitis and one with peritonitis).

\section{DISCUSSION}

This study was conducted prospectively in the department of general surgery SMHS hospital of Govt. Medical College Srinagar J\&K from 2008 to 2018. Ascaris lumbricoides is a specific human helminth and lives in symbiosis with one-fifth of mankind ${ }^{20}$. It is a manifestation of low socioeconomic status and poor sanitary hygiene ${ }^{21}$.

The mean age of patients in our study was 27.9 (range 18-69 years) with S.D of 8 years. Out of 254 patients 170 (67\%) were females and $84(33 \%)$ patients were males (male: female ratio 1:2). Bhansali and Sethna ${ }^{22}$ in their study observed that, majority of cases being in the 3rd and 4th decade of 
life. Our study observed the similar results. Various surgical complications have been ascribed to roundworm infestation. Louw $^{23}$, in a review, found intestinal obstruction, biliary tract diseases, pancreatic diseases, peritonitis and appendicitis due to roundworms. Mishra PK et al. ${ }^{24}$ and Wani I et al. ${ }^{25}$ in their respective studies also found the similar abdominal complications and even the involvement of meckle's diverticulam. In the present study we observed near to same set of abdominal complications.

In this study we found 164 patients (65\% of 254 patients) who presented with hepato-biliary disease. Out of these 164 patients, 129 patients (79\%) had biliary colic, 25 patients (15\%) had cholangitis, $8(5 \%)$ patients had acalcular cholecystitis, and 2 (1\%) patients presented with liver abscess. Out of 254 patients 49(18\%) patients presented with pancreatic disease. Khuroo MS et al. ${ }^{26}$ conducted a study on 500 patients having hepato-biliary-pancreatic ascariasis and they found five clinical presentations in their patients: acute cholecystitis (64 patients), acute cholangitis (121), biliary colic (280), acute pancreatitis (31), and hepatic abscess (4). So our observations were at par with their observations. Out of 164 patients of hepato-biliary disease in present study, 41 patients required ERCP intervention. Almost similar results were observed by Khuroo MS et al. ${ }^{27}$ in their study, in which they observed that out of 156 patients with hepato-biliary and pancreatic ascariasis, 50 patients underwent various endoscopic interventional procedures.

In the present study we found that $53(21 \%)$ patients needed surgical intervention (laproscopy / laprotomy),either on emergency or elective basis. Wani et al. ${ }^{28}$ in their study on presentation and management of 204 patients with biliary ascariasis seen over a period of 5 years from a highly endemic area of Kashmir, and they found that most of their patients responded to conservative management and around one-fifth (20\%) of all patients require surgery. In our study we observed that marginally less number of patients with hepato-biliary and pancreatic disease needed surgical intervention, the reason being that even difficult cases among these patients were managed by ERCP only. Astudillo JA et al. ${ }^{29}$ in their study found that, in 12 patients, conservative management was attempted and was unsuccessful. Endoscopic extraction was successful in four of these patients. Six patients underwent laparoscopic cholecystectomy, common bile duct exploration with parasite extraction, and T-tube placement. In our study we did laproscopic surgery in half of our patients with biliary ascariasis in whom endoscopic extraction was unsuccessful, which is at par with their study. Rest of our patients were operated by laparotomy, as most of them presented to us with acute abdomen like peritonitis, bowel obstruction and meckle's diverticulitis. In present study we found that 27 (10.5\%) patients presented with intestinal obstruction (20 patients with sub-acute obstruction and 7 patients with acute obstruction). Very few studies have been conducted on adults presenting with intestinal obstruction due to ascaris. Mohan lal choudhary et al. ${ }^{30}$ report an adult with intestinal obstruction due to entangled mass of ascaris lumbricoides that presented as a lump in right iliac fossa, managed by laparotomy and milking the worms into colon. Mokoena $\mathrm{T}$ et al. ${ }^{31}$ also conducted a study on adult patients having intestinal obstruction due to ascaris worms. Two patients died in our study, one was having perforation peritonitis and second was having pyogenic cholangitis.

\section{CONCLUSION}

Till date very few studies have been conducted on adult patients presenting with abdominal complaints due to ascariasis infection. Ascaris lumbricoides can present with wide range of clinical symptoms and signs in adult patients, thus posing a big challenge for a physician in diagnosis of the disease. So a clinician in emergency department should consider ascariasis as one of the differential diagnosis in case of acute abdomen in adults in an endemic area, which otherwise he/she is likely to miss in the first contact keeping in view the high prevalence of this disease in tropical and subtropical areas of the world especially India.

\section{REFERENCES}

1. Chawla A, Patwardhan V, Maheshwari M: Primary ascaridial perforation of the small intestine: Sonographic diagnosis. J Clin Ultrasound 2003, 31(1):211-213.

2. Akgun Y: Intestinal obstruction caused by ascaris lumbricoides. Dis Colon Rectum 1996, 39(2):11591163.

3. Steinberg R, Davies J, Millar A: Unusual intestinal sequelae after operations for ascaris lumbricoides infestation. Pediatr Surg Int 2003;19(4):85-87.

4. Guy, K.2011. "Ascaris lumbricoides" (On-line), Animal Diversity Web. Accessed April 15, 2014

5. Coskun A, Ozcan N, Durak AC, Tolu I, Gulec M, Turan $\mathrm{C}$ : Intestinal ascariasis as a cause of bowel obstruction in two patients: sonographic diagnosis. J Clin Ultrasound 1996, 24(3):326-328.

6. Kücükaydin M,Okur H,Icer M:Intestinal complications of ascaris lumbricoides in children. Erciyes Medical Journal 1989;11(6):484-489.

7. Wasadikar PP, Kulkarni AB: Intestinal obstruction due to ascariasis. Br J Surg 1997;84(3):410-412.

8. Peck RJ: Ultrasonography of intestinal ascaris. J Clin Ultrasound 1990;18(5):741-743.

9. J Galiano Gil, C Leyva Esturo, R Peña Ayala. Intestinal Obstruction Due To Ascaris. The Internet Journal of Surgery. 2005;8(2).

10. de Silva NR, Guyatt HL, Bundy DA: Morbidity and mortality due to ascaris-induced intestinal obstruction. Trans R Soc Trop Med Hyg 1997;91(3):31-36.

11. al-Karawi, M, Sanai, FM, Yasawy, MI, Mohammed, AE. Biliary strictures and cholangitis secondary to ascariasis: endoscopic management. Gastrointest Endosc 1999; 50(4):695

12. Javid G, Wani NA, Gulzar GM, et al. Ascaris-induced liver abscess. World J Surg 1999; 23(5):1191.

13. Tietze, PE, Tietze, PH. The roundworm, Ascaris lumbricoides. Prim Care 1991; 18(1):25.

14. Rode H, Cullis S, Millar A, Cremin B, Cywes S: Abdominal complications of ascaris lumbricoides in children. Pediatr Surg Int 1990;5(6):397-401.

15. Villamizar E, Méndez M, Bonilla E, Varon H, de Onatra S: Ascaris lumbricoides infestation as a cause of intestinal obstruction in children: experience with 87 cases. J Pediatr Surg 1996;31(5):201-205. 
16. Cole GJ: Surgical manifestations of ascaris lumbricoides in the intestine. Br J Surg 1965;52(3):444-447.

17. Surendran N, Paulose MO: Intestinal complications of round worms in children.J Pediatr Surg 1988;23(4):931935.

18. Khuroo, MS. Ascariasis. Gastroenterol Clin North Am 1996; 25(2):553.

19. Seltzer, E. Ascariasis. In: Tropical Infectious Diseases: Principles, Pathogens and Practice. 1st ed, Guerrant, RL, Weller, PF (Eds), Philadelphia: Churchill Livingstone; 1999:553.

20. Monroe, LS Gastrointestinal parasites. In: Berk, JW eds. (1985) bockus gastroenterology. Saunders, Philadelphia.

21. Gabaldon, A, Mofidi, C, Morishita, K, Moskovskij, S, Sankalé, M, Standen, DD. Control of ascariasis (report of a WHO expert committee). World health organization technical report series 1967;379(4): pp. 6-7.

22. Bhansali SK, Sethna JR. Intestinal obstruction: a clinical analysis of 348 cases. Indian J Surg 1970;32(6):57-70.

23. Louw, JH. Abdominal complications of Ascaris lumbricoides infestation in children. $\mathrm{Br} \mathrm{J}$ Surg 1966;53(2):510-521.

24. Mishra PK, Agrawal A, Joshi M, Sanghvi B, Shah H, Parelkar SV. Intestinal obstruction in children due to Ascariasis: A tertiary health centre experience. Afr J Paediatr Surg. 2008;5(3):65-70.

25. Wani I, Šnábel V, Naikoo G, Wani S, Wani M, Amin A, et al. Encountering Meckel's diverticulum in emergency surgery for ascaridial intestinal obstruction. World J Emerg Surg. 2010;5(2):15.

26. Khuroo MS, Zargar SA, Mahajan R. Hepatobiliary and pancreatic ascariasis in India. Lancet. 1990;335(8704):1503-1506.

27. Khuroo MS, Zargar SA, Yattoo GN, Javid G, Dar MY, Boda MI, et al. Worm extraction and biliary drainage in hepatobiliary and pancreatic ascariasis. Gastrointest Endosc. 1993;39(4):680-5.

28. Wani NA, Chrungoo RK.Biliary ascariasis: surgical aspects. World J Surg. 1992:16(5):976-9.

29. Astudillo JA, Sporn E, Serrano B, Astudillo R. Ascariasis in the hepatobiliary system: laparoscopic management. J R Coll Surg Edinb 2008:207(4):527-32.

30. Mohan Lal Choudhary et al. Intestinal Obstruction Due To Ascaris Lumbricoides Infestation In Adult Presenting As Lump In Right Iliac Fossa. Journal of Surgery Pakistan (International) 2013:18 (2):105-106.

31. Mokoena T, Luvuno FM. Conservative management of intestinal obstruction due to Ascaris worms in adult patients: a preliminary report. J R Coll Surg Edinb 1988;33(1):318-321.

Source of Support: Nil; Conflict of Interest: None

Submitted: 20-05-2018; Accepted: 24-06-2018; Published online: 05-07-2018 